\title{
Development of a magnesium-alumina composite through cold consolidation of machining chips by high-pressure torsion
}

\author{
Moara M. de Castro ${ }^{1}$, Pedro Henrique R. Pereira ${ }^{1,2}$, Augusta C. Isaac Neta ${ }^{1}$, \\ Roberto B. Figueiredo ${ }^{1, *}$, Terence G. Langdon ${ }^{2}$ \\ ${ }^{1}$ Department of Metallurgical and Materials Engineering, \\ Universidade Federal de Minas Gerais, Belo Horizonte, MG 31270-901, Brazil \\ ${ }^{2}$ Materials Research Group, Department of Mechanical Engineering, \\ University of Southampton, Southampton SO17 1BJ, UK
}

\begin{abstract}
.
High pressure torsion offers unique conditions for the consolidation of metallic particles at room temperature owing to the high hydrostatic compressive stresses combined with the high shear strain. $\mathrm{A} \mathrm{Mg}-\mathrm{Al}_{2} \mathrm{O}_{3}$ composite was produced by consolidation of machining chips of pure magnesium with $10 \%$ in volume of alumina particles. The consolidation process was investigated by optical and scanning electron microscopy and X-ray microtomography. It is shown that shear deformation concentrates along thick alumina particle layers in the initial stage of deformation. A significant fraction of the hard phase particles are pushed into the outflow in quasiconstrained HPT and a homogeneous composite is achieved after significant straining. The composite exhibits a refined microstructure, a higher hardness and improved resistance against room temperature creep compared to pure magnesium.
\end{abstract}

Keywords: alumina; consolidation; metal matrix composite; magnesium; high-pressure torsion;

*corresponding author: figueiredo@demet.ufmg.br 


\section{Introduction}

Magnesium, the lightest structural metallic material, has attracted renewed interest in the automotive and aerospace sectors owing to the increasing worldwide demand for a reduction in fuel consumption and $\mathrm{CO}_{2}$ emissions. Nevertheless, any replacement of the currently dominant steels and aluminum alloys has proven difficult because of the inherent low strength. Different approaches have been developed to overcome these limitations but generally there has been a special emphasis on alloy development and/or an optimization of the processing techniques for achieving enhanced grain refinement and strain hardening. Another potential strengthening route that has begun to attract significant attention is the addition of a hard-reinforcing phase, typically a ceramic, to produce the so-called metal matrix composites (MMCs).

Among the different production routes hitherto developed for the manufacturing of MMCs, severe plastic deformation (SPD) processes have emerged as powerful tools for the consolidation of composites from metal chips, particles or powders [1]. In particular, equalchannel angular pressing (ECAP) [2] has been used for the consolidation of different metals [3] including magnesium [4]. Due to the high pressure and high shear strain exerted in the ECAP processing technique, a binding of the particles is achieved which leads to the production of bulk samples. In practice, it is found that the application of ECAP at higher temperatures, and with the simultaneous aid of a back-pressure, provides the optimum conditions for achieving consolidation.

Processing by high-pressure torsion (HPT) [5] offers an alternative procedure for consolidating metal particles at room temperature because of the ability in HPT to impose extremely high hydrostatic pressures. In the HPT process, the nominal pressure is usually in the range of $\sim 2$ - 8 GPa which is well above the flow stress of most metallic materials. This means 
that the particles will be plastically deformed to an almost fully-dense bulk solid. Furthermore, the torsional straining of the particles increases their surface area to promote the binding of the particles and the application of SPD will lead to a refined microstructure in the matrix. For example, it was shown earlier that milled Al-7.5\% Mg powders may be consolidated by applying 5 turns of HPT at a pressure of 6 GPa [6].

There are now several reports documenting the production of MMCs using HPT processing. Thus, a Co-NiO composite was produced by 5 turns of HPT at 6 GPa [7], an Al-

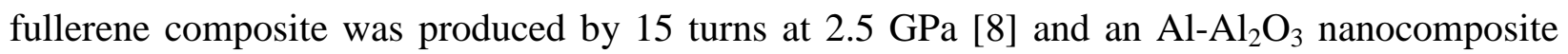
was fabricated by using 10 turns at $6 \mathrm{GPa}$ [9]. There are also reports of the use of HPT for the consolidation of machining chips: for example, copper machining chips were consolidated by 5 turns of HPT at a pressure of $6 \mathrm{GPa}$ at room temperature [10], Al-8\% Si-3\% Cu chips were consolidated by 10 turns at a pressure of $8 \mathrm{GPa}$ [11] and $\mathrm{Zr}_{50} \mathrm{Cu}_{30} \mathrm{Al}_{10} \mathrm{Ni}_{10}$ metallic glass chips were consolidated by 10 turns at a pressure of 6 GPa [12].

Earlier studies demonstrated that Mg powders are effectively consolidated by HPT [1315] leading to the formation of Mg-MgO composites in which an oxide layer forms naturally around the Mg particles and acts as a reinforcing phase. Nevertheless, despite the very great potential for using HPT in producing Mg-based MMCs at room temperature, investigations on magnesium reinforced with higher contents of ceramic particles has remained essentially unexplored. Accordingly, the present research was initiated with the objective of fabricating Mgbased MMCs by using HPT for the consolidation of magnesium machining chips using alumina as the reinforcing phase. 


\section{Experimental materials and procedures}

Commercial purity magnesium was machined by dry milling and the chips were collected. Care was taken to clean the machine before milling and to avoid the use of a lubricant in order to prevent any contamination of the chips. The machining chips were mixed with alumina $\left(\mathrm{Al}_{2} \mathrm{O}_{3}\right)$ powder in a 9 to 1 ratio in weight in a rotating enclosed bottle. The chips were hundreds of micrometers in length and the alumina particles had diameter of less than $1 \mu \mathrm{m}$. Observation using a stereomicroscope showed the alumina powder covered the surface of the machining chips and no powder remained in the bottle after mixing. The product was precompacted using a pressure of $\sim 250 \mathrm{MPa}$ into $10 \mathrm{~mm}$ diameter discs with thicknesses of $\sim 1.0$ mm. The pre-compacted discs were then processed by HPT at room temperature using a quasiconstrained facility [16] operating at a nominal pressure of $6.0 \mathrm{GPa}$ and using a rotation speed of $1 \mathrm{rpm}$. Samples were processed to 1/8, 1 and 5 turns in order to rigorously track the evolution of the consolidation. For comparison purposes, a disc of bulk pure magnesium was also processed by HPT to 5 turns. The local heating induced by plastic deformation is expected to be less than $20^{\circ} \mathrm{C}$ considering a flow stress of $200 \mathrm{MPa}$ for magnesium [17].

The three-dimensional (3D) distributions of alumina particles and voids in the processed samples were evaluated using a SkyScan 1174 micro-CT scanner (Bruker, Germany). This system is equipped with a $50 \mathrm{kV} / 40 \mathrm{~W}$ tungsten X-ray source and a cooled 1.3-megapixel CCD camera coupled to a scintillator by a lens with a 1:6 zoom range. In order to provide comprehensive results, approximately 1000 projections were recorded at angular increments of $1 / 4^{\circ}$ between $0^{\circ}$ and $360^{\circ}$. Samples of about $10 \mathrm{~mm}$ in diameter were recorded at $70 \mathrm{kV}$ and 140 $\mu \mathrm{m}$ using an aluminum filter of $0.5 \mathrm{~mm}$ thickness to reduce any beam hardening artifacts. An Xray magnification of $6 \times$ and a lens magnification of $4 \times$ were used to give a field of view of about 
$10 \mathrm{~mm}$. A pixel size of about $7 \mu \mathrm{m}$ was achieved. Although the spatial resolution of the X-ray images was about $14 \mu \mathrm{m}$, and therefore nearly twice the size of the pixels, this was larger than the size of the individual alumina particles and this method was therefore effective in indentifying any large pores and alumina agglomerates.

The longitudinal sections of the discs were ground and polished and observed using optical and scanning electron microscopy operating at $15 \mathrm{kV}$ with backscattered electron imaging. The discs processed through 5 turns of HPT were also analysed by X-ray diffraction. MAUD software was used to estimate the crystal structure parameters, the crystallite sizes and the lattice microstrains. Microhardness testing, with a load of $200 \mathrm{gf}$ and a dwell time of $10 \mathrm{~s}$, was used to determine and compare the hardness of pure magnesium and the magnesium-based composite. Dynamic hardness testing was used to determine the room temperature creep properties on longitudinal sections of the consolidated discs. For the creep tests, a constant load of $300 \mathrm{mN}$ was applied during $500 \mathrm{~s}$ and the penetration depth was tracked. The creep data were then obtained by converting the instantaneous hardness into flow stress and converting the depth and time data into strain rate $[18,19]$.

\section{Experimental results}

\subsection{Nature of the consolidation process}

Figure 1 shows representative $\mathrm{X}$-ray microtomography images of the plan views (upper) and side sections (lower) of the discs processed through 1/8, 1 and 5 turns of HPT. Any agglomerated alumina shows up in a dark colour with an irregular shape and it is present throughout the sample processed to $1 / 8$ turn. Further processing to 1 turn leads to the formation of a large agglomeration arranged concentrically in the disc sample where the spiral shape of the track suggests that the rotation occurring during HPT gradually pushes the alumina towards the 
edge of the sample. This suggests that the processing of a two-phase composite during HPT can promote the agglomeration of the phases due to their different flow behavior. A small volume of the material occurs as an outflow around the periphery of the disc in quasi-constrained HPT and it is likely that this outflow contained a significant fraction of the reinforcement particles that had flowed together within the disc. The disc processed to 5 turns exhibits only limited alumina agglomeration and furthermore any agglomeration tends to be concentrated in isolated positions near the edge of the disc.

The consolidation of the chips and the distributions of the alumina particles were also evaluated along longitudinal sections of the discs using optical and scanning electron microscopy. Figure 2 shows low magnification images of the processed discs where pores and any separation between the chips are visible as dark areas. The disc processed to 1/8 turn is characterised by a severe lack of bonding between the chips and also the area near the disc centre appears even less consolidated so that a small number of chips was removed from the disc during grinding and polishing. This image demonstrates conclusively that processing through $1 / 8$ turn is insufficient to achieve a reasonable level of consolidation. The disc processed to 1 turn displays improved consolidation especially near the edge regions although some pores are visible near the centre. Finally, processing to 5 turns lead to an apparent full consolidation of the machining chips throughout the sample although a small amount of ceramic particle agglomeration may remain in the vicinity of the disc centre.

\subsection{Microstructural characterization after HPT processing}

Details of the microstructures near the edges of the processed discs are depicted in Fig. 3 where the upper images are after 1/8 and 1 turn and the lower images are after 5 turns at two different magnifications. There is a clear distinction between the large magnesium volumes and 
the alumina particles which are concentrated between these areas in the sample processed to 1/8 turn. Thus, the alumina-rich areas prevent bonding of the magnesium chips and an elongated gap is visible at the bottom of the image. Increasing the shear straining to 1 turn of HPT leads to the formation of bonding between the magnesium chips and the dispersion of the alumina particles although some tracks of alumina are again visible. Further processing to 5 turns leads to a complete bonding of the magnesium chips as shown in the lower images. Thus, although some ceramic particles may remain partially agglomerated near the disc centre, there is a homogeneous distribution near the edges and throughout almost all of the disc. Detailed inspection of the microstructure near the centre of the disc processed to 5 turns revealed some distinct particles of alumina but the total amount of the ceramic particles was significantly less than the initial value of $10 \%$. Image analysis of the longitudinal section of the disc processed through 5 turns revealed a surface fraction of $\mathrm{Al}_{2} \mathrm{O}_{3}$ of $\sim 3.5 \%$ near the centre of the disc but a fraction of only $\sim 0.5 \%$ near the edge.

Figure 4 shows the $\mathrm{X}$ ray diffraction (XRD) patterns of the discs of pure magnesium (upper) and the $\mathrm{Mg}-\mathrm{Al}_{2} \mathrm{O}_{3}$ composite (lower) after processing through 5 turns. The relative intensities of the peaks appear similar in both discs suggesting the presence of similar textures. A few small peaks associated with the $\mathrm{Al}_{2} \mathrm{O}_{3}$ were identified in the lower pattern and are marked by blue dots. The low intensities of these $\mathrm{Al}_{2} \mathrm{O}_{3}$ peaks suggest that only a minor fraction of the composite is composed of this phase and this is consistent with the microtomography that provides evidence for alumina agglomerates appearing in the outflow around the periphery of the disc during processing in HPT. The lattice parameters, crystallite size and lattice microstrain were estimated using the Rietveld refinement method. The experimental points (symbols), simulated profiles (lines) and the difference between them are also depicted in Fig. 4 and these 
data are summarized in Table 1 . Thus, the crystal parameters are generally similar in the bulk magnesium and the magnesium composite although the crystallite size is smaller and the lattice microstrain is larger in the composite. The similar crystal parameters negate the formation of a solid solution in the magnesium matrix.

\subsection{Hardness values and creep data after HPT processing}

The distribution of hardness values in the radial directions of discs of bulk magnesium and of the $\mathrm{Mg}-\mathrm{Al}_{2} \mathrm{O}_{3}$ composite are depicted in Fig. 5. Pure magnesium exhibits a saturation in hardness at $\sim 48 \mathrm{Hv}$ after 5 turns of HPT and this value remains essentially constant across the disc. This saturation value is in agreement with other reports of the HPT processing of pure magnesium [20, 21]. By contrast, the magnesium composite shows no evidence of a hardness saturation and instead the hardness increases and reaches a maximum at the edge of the disc. Initially, the microhardness values near the centre of the $\mathrm{Mg}-\mathrm{Al}_{2} \mathrm{O}_{3}$ disc are lower than for the pure metal after processing under equivalent conditions and this indicates that the grain refinement kinetics in the composite are initially delayed due to the occurrence of particle binding. It also appears that a full consolidation was not achieved in this region of the $\mathrm{Mg}-\mathrm{Al}_{2} \mathrm{O}_{3}$ composite after 5 revolutions of HPT. Conversely, the hardness in the $\mathrm{Mg}$ composite is significantly larger than for pure magnesium at the edge of the disc which shows the hardness saturation in the composite requires a higher level of shear strain although the maximum attainable hardness is then at an increased value.

Dynamic hardness testing was used to evaluate creep at room temperature in the magnesium matrix. Figure 6(a) shows the depth versus time data and the trend curves for indentations near the edges of the discs of pure magnesium and the composite processed by 5 turns of HPT. The depth increases with time of application of a constant load due to the 
occurrence of room temperature creep and it is apparent that this effect is more pronounced in the pure material. These data were converted into flow stress versus strain rate and the relevant curves are plotted in Fig. 6(b). The results show that the flow stresses for the $\mathrm{Mg}^{-} \mathrm{Al}_{2} \mathrm{O}_{3}$ composite are higher than for pure magnesium but the strain rate sensitivity is lower. It is readily apparent that the hard particles are more effective in increasing the low strain rate flow stress. It was noted earlier that an increase in strain rate sensitivity is associated with a change in deformation mechanism at room temperature in pure magnesium [19,22]. It is worth noting also that the strain rate sensitivity of the composite in this investigation is high compared to conventional coarse-grained magnesium where earlier results showed $m \approx 0.03$ [19].

\section{Discussion}

The consolidation of metallic particles $[14,15,23,24]$ and chips $[10,11]$ into bulk samples was reported earlier and there are also reports of the incorporation of metallic particles and hard phase particles into metal matrix composites by HPT [8, 9, 13, 25]. Nevertheless, the present results demonstrate that it is feasible to mix magnesium chips and hard ceramic particles in order to produce bulk nano-composites by HPT. It is noted, however, that the larger size of the chips increases the difficulty both of bonding the metallic phase and of achieving a homogeneous mixing of the phases.

Prior to HPT processing, the Mg chips were hundreds of micrometers in length whilst the alumina particles had less than $1 \mu \mathrm{m}$ in diameter. This leads to an inhomogeneous distribution of phases in the pre-compacted discs. The initial division of phases leads to the build up of a thick layer of a hard ceramic phase between the large chips and these layers then prevent full contact between the metallic phase during the early stage of processing. As a consequence, the chips initially slide over the loose ceramic particles without incurring any significant plastic 
deformation. The thickness of the ceramic particle layer gradually decreases due to the build up of large agglomerations which are pushed towards the edge of the sample and binding between the chips then starts to develop. Accordingly, a dense metallic matrix network is only observed in some areas of the disc after a full turn of HPT. The microstructure at this stage remains heterogeneous since there is a clear distinction between the areas rich in ceramic particles and the areas of pure magnesium. The mixing of these phases is only achieved after additional significant straining up to 5 turns of HPT. It is important to note also that an earlier consolidation of pure magnesium particles and powders was achieved with a total shear strain of only 42 [15] while the composite in the current investigation required a total shear strain of $\sim 196$ at the edge of the disc.

Observations of the microstructure of the disc processed to 5 turns of HPT suggest that the total volume of alumina particles decreases during processing. Thus, the initial sample was prepared with $10 \%$ of total volume of alumina particles but a smaller fraction was observed after HPT processing. It is reasonable to anticipate that a small fraction of alumina particles may be removed from the surface of the sample during metallographic preparation but this effect cannot account for this significant difference. The evidence from X-ray diffraction also suggests that the alumina phase is only a minor fraction of the sample after 5 turns of HPT. Some fragmentation of the $\mathrm{Al}_{2} \mathrm{O}_{3}$ phase may take place during HPT and X-ray diffraction and SEM may underestimate the amount of these nanometer sized particles. However, the presence of a considerable volume of particles with no sign of significant reduction in size suggests that any fragmentation was not extensive. Therefore, this reduction in the volume fraction of the hard phase is attributed to the preferential outflow which occurs in quasi-constrained HPT at the edges 
of the sample. Furthermore, this is in agreement with the observation of a spiral of alumina in the microtomography image in Fig. 1 after 1 turn.

Although a large fraction of the reinforcement phase was lost during processing, a homogeneous distribution of alumina particles was attained within the magnesium matrix at the edge of the sample processed to 5 turns. The reinforcement phase led to a decrease in the crystallite size and an increase in the lattice microstrain compared to the bulk pure magnesium. As a consequence, the composite displays different mechanical behavior.

It is known that pure magnesium exhibits a saturation in hardness at low levels of strain when processing by HPT. Typical values of hardness for HPT-processed pure magnesium are within the range $\sim 35$ - $55 \mathrm{Hv}[20,21,26]$. By contrast, the hardness at the edge of the $\mathrm{Mg}^{-} \mathrm{Al}_{2} \mathrm{O}_{3}$ composite in these experiments was $\sim 75 \mathrm{Hv}$. In addition, the composite exhibits a higher resistance against room temperature creep. Recent reports have shown that pure magnesium changes the deformation behavior with grain refinement [19, 22, 27-29] and becomes extremely ductile, where this change in behavior is attributed to the onset of room temperature creep by grain boundary sliding [23]. The flow stress versus strain rate curve of the $\mathrm{Mg}-\mathrm{Al}_{2} \mathrm{O}_{3}$ composite in Fig. 6(b) shows an increase in the low strain rate flow stress and a decrease in the strain rate sensitivity. This suggests that the presence of hard particles in the present experiments serves to hinder the occurrence of grain boundary sliding. It is known that a fine dispersion of hard particles promotes a local strain gradient in the metallic matrix which increases the hardening rate and strengthening [30]. This is in agreement with the larger lattice microstrain and the higher hardness observed in the $\mathrm{Mg}^{-} \mathrm{Al}_{2} \mathrm{O}_{3}$ composite in the present investigation. 


\section{Summary and conclusions}

1. A Mg- $\mathrm{Al}_{2} \mathrm{O}_{3}$ composite was produced by consolidation of pure magnesium chips and alumina particles using high-pressure torsion. The microstructural evolution was examined by optical microscopy, scanning electron microscopy and X-ray microtomography.

2- The initial segregation of phases leads initially to the sliding of magnesium chips along thick layers of loose alumina particles. The thickness of these alumina particle layers decreases gradually as this phase is preferentially pushed into the outflow which occurs around the periphery of the disc in quasi-constrained HPT. The results show the bonding between the magnesium chips and the mixing of the phases requires a relatively large amount of shear strain.

3. The $\mathrm{Mg}-\mathrm{Al}_{2} \mathrm{O}_{3}$ composite exhibits a smaller crystallite size, a higher lattice microstrain and a higher hardness by comparison with bulk pure magnesium processed by HPT. The Mg$\mathrm{Al}_{2} \mathrm{O}_{3}$ composite also displays enhanced resistance against room temperature creep compared to bulk magnesium.

\section{Acknowledgements}

The authors thank the Microscopy Centre of UFMG for experimental assistance. This work was supported by the Serrapilheira Institute (grant number Serra-1709-17750), CNPq, FAPEMIG and CAPES-Proex. One of the authors was supported by the European Research Council under ERC Grant Agreement No. 267464-SPDMETALS (TGL).

\section{Declarations of interest: none}




\section{REEFERENCES}

[1] R.Z. Valiev, R.K. Islamgaliev, I.V. Alexandrov, Bulk nanostructured materials from severe plastic deformation, Progress in Materials Science 45 (2000) 103-187.

[2] R.Z. Valiev, T.G. Langdon, Principles of equal-channel angular pressing as a processing tool for grain refinement, Progress in Materials Science 51 (2006) 881-981.

[3] X.L. Wu, K. Xia, Synthesis of Bulk Materials by Equal Channel Angular Consolidation of Particles, Materials Science Forum 503-504 (2006) 233-238.

[4] H.C. Lee, C.G. Chao, T.F. Liu, C.Y. Lin, H.C. Wang, Effect of Temperature and Extrusion Pass on the Consolidation of Magnesium Powders Using Equal Channel Angular Extrusion, Materials Transactions 54 (2013) 765-768.

[5] A.P. Zhilyaev, T.G. Langdon, Using high-pressure torsion for metal processing: Fundamentals and applications, Progress in Materials Science 53 (2008) 893-979.

[6] Z. Lee, F. Zhou, R.Z. Valiev, E.J. Lavernia, S.R. Nutt, Microstructure and microhardness of cryomilled bulk nanocrystalline $\mathrm{Al}-7.5 \% \mathrm{Mg}$ alloy consolidated by high pressure torsion, Scripta Materialia 51 (2004) 209-214.

[7] E. Menéndez, J. Sort, V. Langlais, A. Zhilyaev, J.S. Muñoz, S. Suriñach, J. Nogués, M.D. Baró, Cold compaction of metal-ceramic (ferromagnetic-antiferromagnetic) composites using high pressure torsion, Journal of Alloys and Compounds 434-435 (2007) 505-508.

[8] T. Tokunaga, K. Kaneko, K. Sato, Z. Horita, Microstructure and mechanical properties of aluminum-fullerene composite fabricated by high pressure torsion, Scripta Materialia 58 (2008) 735-738.

[9] M. Ashida, Z. Horita, T. Kita, A. Kato, Production of $\mathrm{Al} / \mathrm{Al}_{2} \mathrm{O}_{3}$ Nanocomposites through Consolidation by High-Pressure Torsion, Materials Transactions 53 (2012) 13-16.

[10] A.P. Zhilyaev, A.A. Gimazov, G.I. Raab, T.G. Langdon, Using high-pressure torsion for the coldconsolidation of copper chips produced by machining, Materials Science and Engineering: A 486 (2008) 123-126. 
[11] M.I. Abd El Aal, E.Y. Yoon, H.S. Kim, Recycling of $\mathrm{AlSi}_{8} \mathrm{Cu}_{3}$ alloy chips via high pressure torsion, Materials Science and Engineering: A 560 (2013) 121-128.

[12] K. Edalati, Y. Yokoyama, Z. Horita, High-pressure torsion of machining chips and bulk discs of amorphous $\mathrm{Zr}_{50} \mathrm{Cu}_{30} \mathrm{Al}_{10} \mathrm{Ni}_{10}$, Materials Transactions 51 (2010) 23-26.

[13] J.X. Zou, C.F. Pérez-Brokate, R. Arruffat, B. Bolle, J.J. Fundenberger, X.Q. Zeng, T. Grosdidier, W.J. Ding, Nanostructured bulk Mg+MgO composite synthesized through arc plasma evaporation and high pressure torsion for H-storage application, Materials Science and Engineering: B 183 (2014) 1-5.

[14] T. Grosdidier, J.J. Fundenberger, J.X. Zou, Y.C. Pan, X.Q. Zeng, Nanostructured Mg based hydrogen storage bulk materials prepared by high pressure torsion consolidation of arc plasma evaporated ultrafine powders, International Journal of Hydrogen Energy 40 (2015) 16985-16991.

[15] S. Panda, J.-J. Fundenberger, Y. Zhao, J. Zou, L.S. Toth, T. Grosdidier, Effect of initial powder type on the hydrogen storage properties of high-pressure torsion consolidated Mg, International Journal of Hydrogen Energy 42 (2017) 22438-22448.

[16] R.B. Figueiredo, P.R. Cetlin, T.G. Langdon, Using finite element modeling to examine the flow processes in quasi-constrained high-pressure torsion, Materials Science and Engineering A 528 (2011) 8198-8204.

[17] P.H.R. Pereira, R.B. Figueiredo, Y. Huang, P.R. Cetlin, T.G. Langdon, Modeling the temperature rise in high-pressure torsion, Materials Science and Engineering A 593 (2014) 185-188.

[18] H. Somekawa, T. Mukai, Effect of grain boundary structures on grain boundary sliding in magnesium, Materials Letters 76 (2012) 32-35.

[19] R.B. Figueiredo, F.S.J. Poggiali, C.L.P. Silva, P.R. Cetlin, T.G. Langdon, The influence of grain size and strain rate on the mechanical behavior of pure magnesium, Journal of Materials Science 51 (2016) 3013-3024. 
[20] K. Edalati, A. Yamamoto, Z. Horita, T. Ishihara, High-pressure torsion of pure magnesium: Evolution of mechanical properties, microstructures and hydrogen storage capacity with equivalent strain, Scripta Materialia 64 (2011) 880-883.

[21] X.G. Qiao, Y.W. Zhao, W.M. Gan, Y. Chen, M.Y. Zheng, K. Wu, N. Gao, M.J. Starink, Hardening mechanism of commercially pure Mg processed by high pressure torsion at room temperature, Materials Science and Engineering A 619 (2014) 95-106.

[22] R.B. Figueiredo, S. Sabbaghianrad, A. Giwa, J.R. Greer, T.G. Langdon, Evidence for exceptional low temperature ductility in polycrystalline magnesium processed by severe plastic deformation, Acta Materialia 122 (2017) 322-331.

[23] J.M. Cubero-Sesin, Z. Horita, Powder consolidation of Al-10wt\% Fe alloy by High-Pressure Torsion, Materials Science and Engineering A 558 (2012) 462-471.

[24] M. Khajouei-Nezhad, M.H. Paydar, R. Ebrahimi, P. Jenei, P. Nagy, J. Gubicza, Microstructure and mechanical properties of ultrafine-grained aluminum consolidated by high-pressure torsion, Materials Science and Engineering A 682 (2017) 501-508.

[25] T. Tokunaga, K. Kaneko, Z. Horita, Production of aluminum-matrix carbon nanotube composite using high pressure torsion, Materials Science and Engineering A 490 (2008) 300-304.

[26] L.R.C. Malheiros, R.B. Figueiredo, T.G. Langdon, Processing different magnesium alloys through HPT, Materials Science Forum 783-786 (2014) 2617-2622.

[27] H. Somekawa, T. Mukai, Hall-Petch Breakdown in Fine-Grained Pure Magnesium at Low Strain Rates, Metallurgical and Materials Transactions A 46A (2015) 894-902.

[28] C.L.P. Silva, A.C. Oliveira, C.G.F. Costa, R.B. Figueiredo, M. de Fátima Leite, M.M. Pereira, V.F.C. Lins, T.G. Langdon, Effect of severe plastic deformation on the biocompatibility and corrosion rate of pure magnesium, Journal of Materials Science 52 (2017) 5992-6003.

[29] Z. Zeng, J.-F. Nie, S.-W. Xu, C. H. J. Davies, N. Birbilis, Super-formable pure magnesium at room temperature, Nature Communications 8 (2017) 972. 
[30] N. A. Fleck, G. M. Muller, M. F. Ashby, J. W. Hutchinson, Strain gradient plasticity: theory and experiment, Acta Metallurgica et Materialia 42 (1994) 475-487. 
Table 1 - Crystallite size, $d_{X R D}$, unit cell parameters, $a$ and $c$, and lattice microstrain, $\varepsilon$, for pure magnesium and the $\mathrm{Mg}-\mathrm{Al}_{2} \mathrm{O}_{3}$ composite.

\begin{tabular}{|c|c|c|c|c|}
\hline & $\begin{array}{c}\mathrm{d}_{\text {XRD }} \\
(\mathrm{nm})\end{array}$ & $\mathrm{a}(\mathrm{nm})$ & $\mathrm{c}(\mathrm{nm})$ & $\varepsilon \times 10^{-4}$ \\
\hline $\mathrm{Mg}$ & 206 & 0.32138 & 0.52152 & 4.10 \\
\hline $\mathrm{Mg}-\mathrm{Al}_{2} \mathrm{O}_{3}$ & 158 & 0.32111 & 0.52128 & 7.17 \\
\hline
\end{tabular}


$\mathrm{Mg}-\mathrm{Al}_{2} \mathrm{O}_{3}$

HPT: $P=6 \mathrm{GPa}$ (R.T.) $1 \mathrm{rpm}$

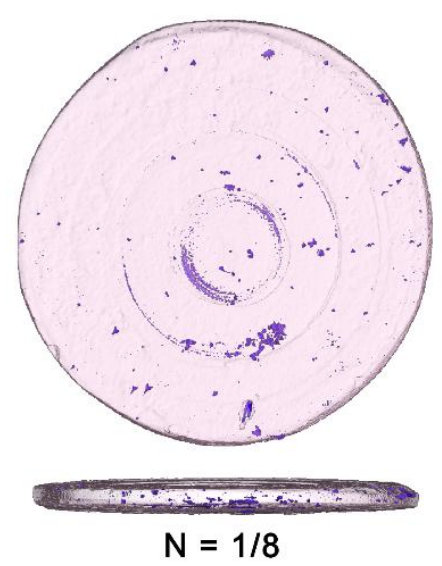

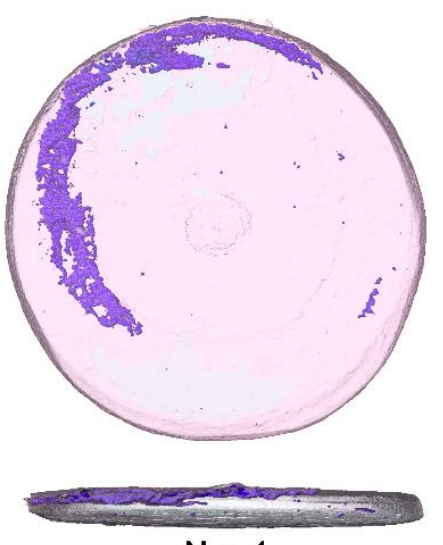

$\mathrm{N}=1$

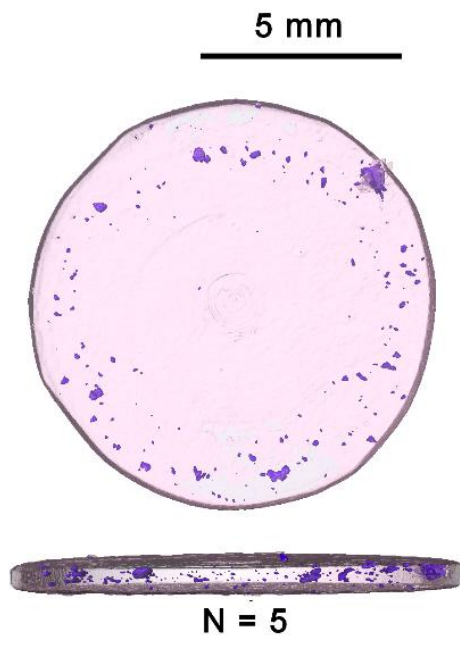

Figure $1-X$-ray microtomography images of discs processed to $1 / 8,1$ and 5 turns of HPT. 


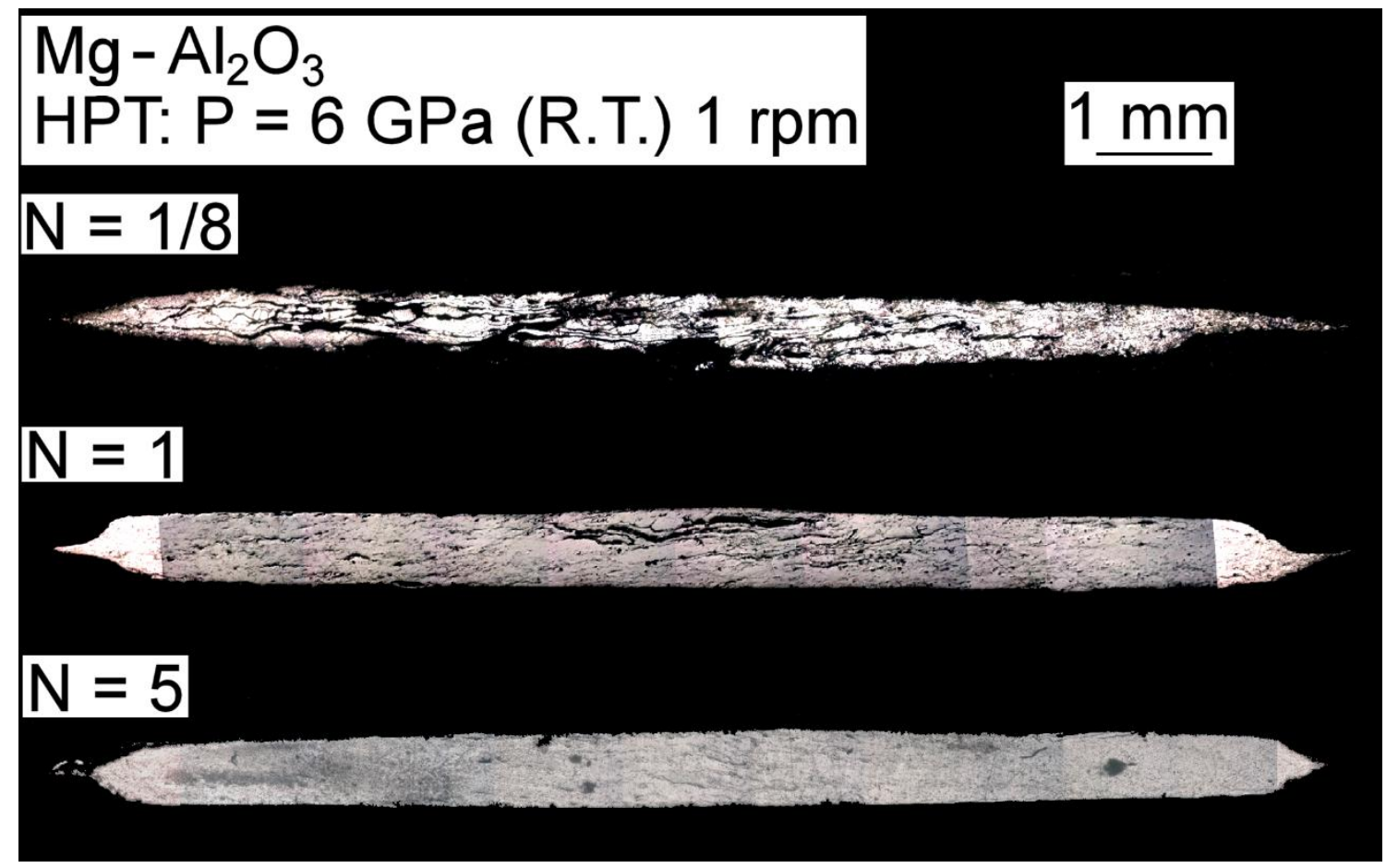

Figure 2 - Optical microscopy images of the longitudinal sections of discs processed to $1 / 8,1$ and 5 turns of HPT. 
$\mathrm{Mg}-\mathrm{Al}_{2} \mathrm{O}_{3}$

HPT: $\mathrm{P}=6 \mathrm{GPa}$ (R.T.) $1 \mathrm{rpm}$
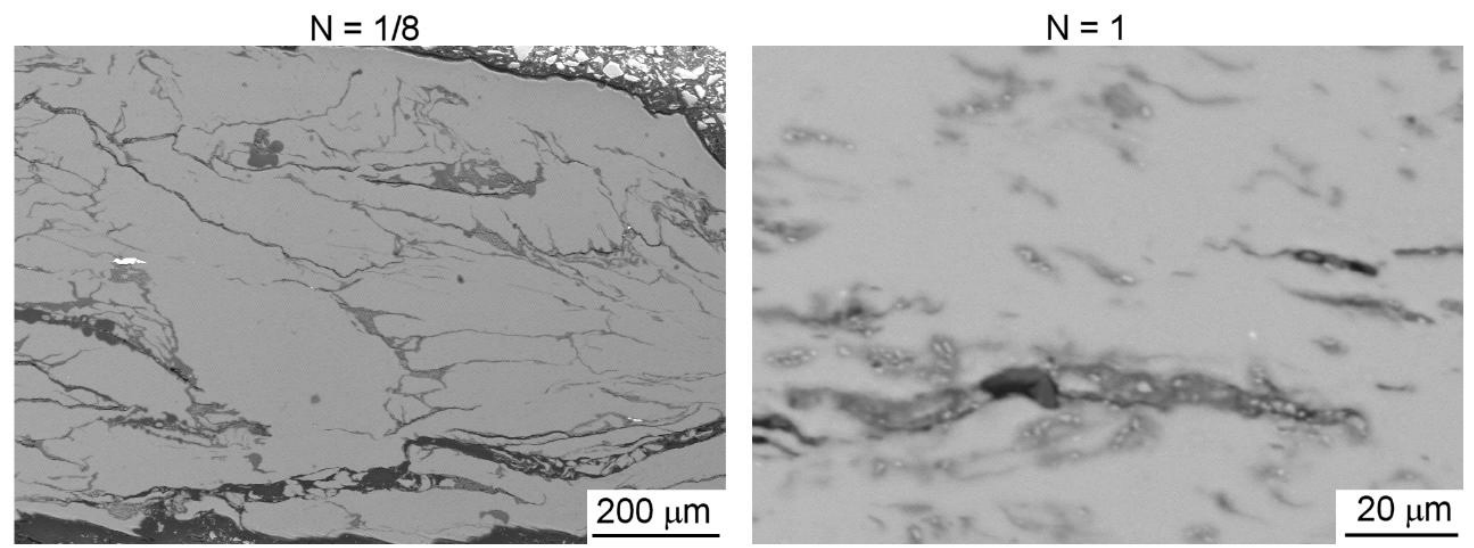

$N=5$

$$
N=5
$$
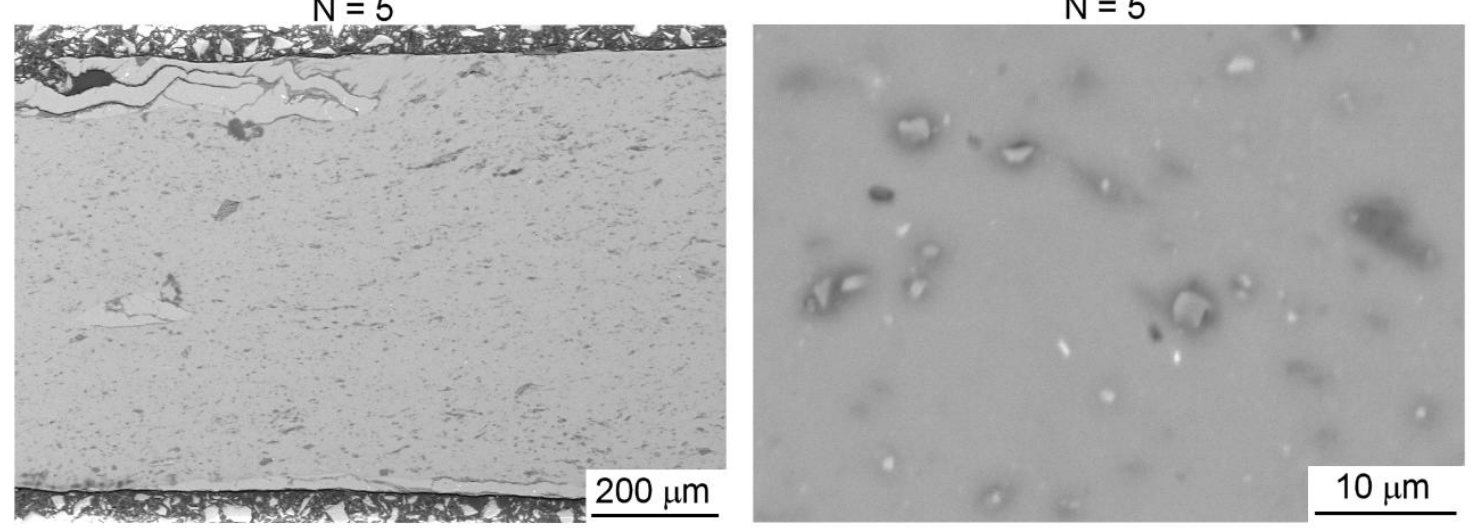

Figure 3 - Scanning electron microscopy images of the microstructures of discs processed to different numbers of HPT turns. 


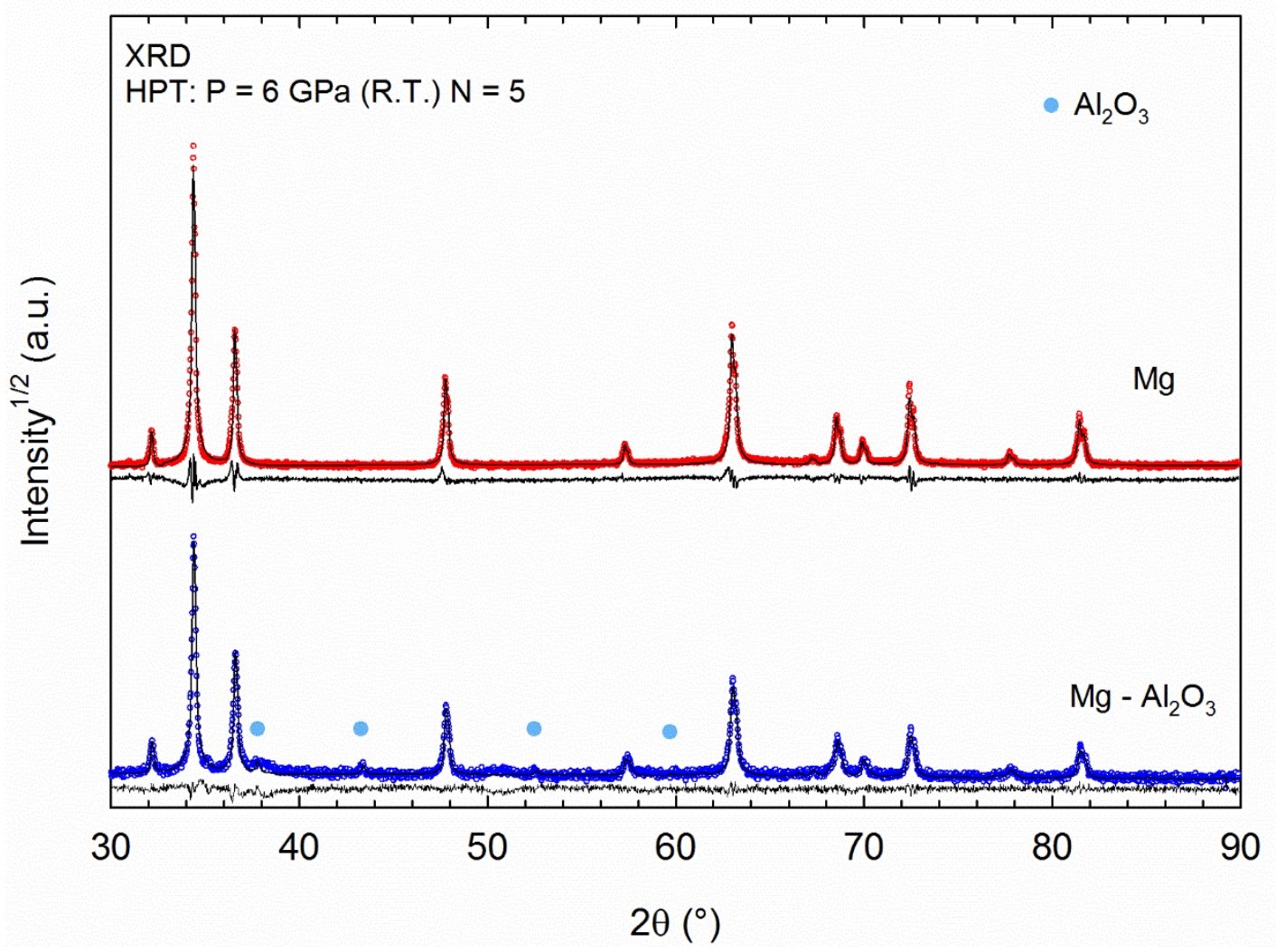

Figure $4-X$-ray diffraction patterns and simulated patterns of discs processed by 5 turns of HPT. 


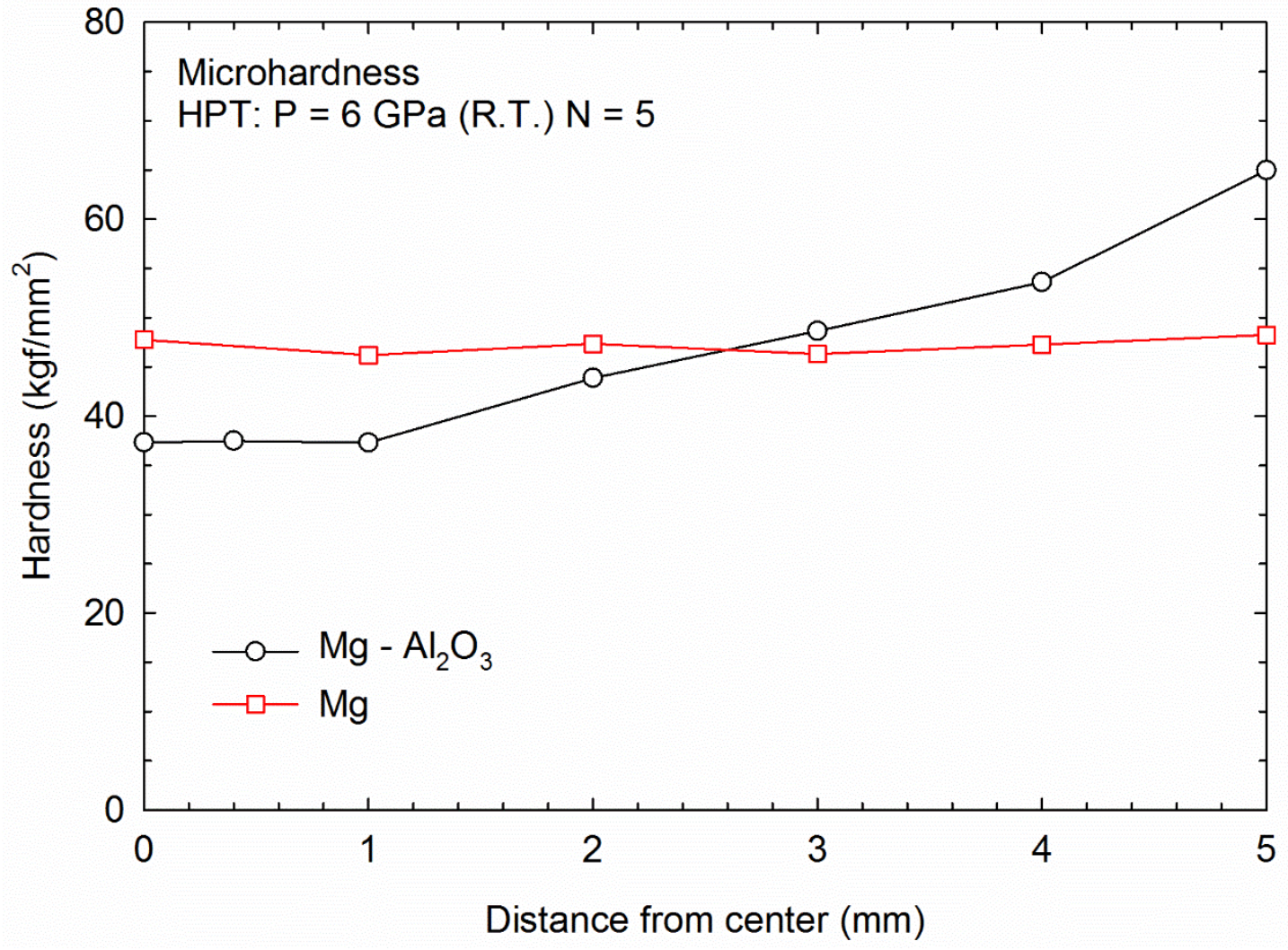

Figure 5 - Microhardness plotted as a function of the distance from the center of discs of pure magnesium and magnesium composite processed to 5 turns of HPT. 

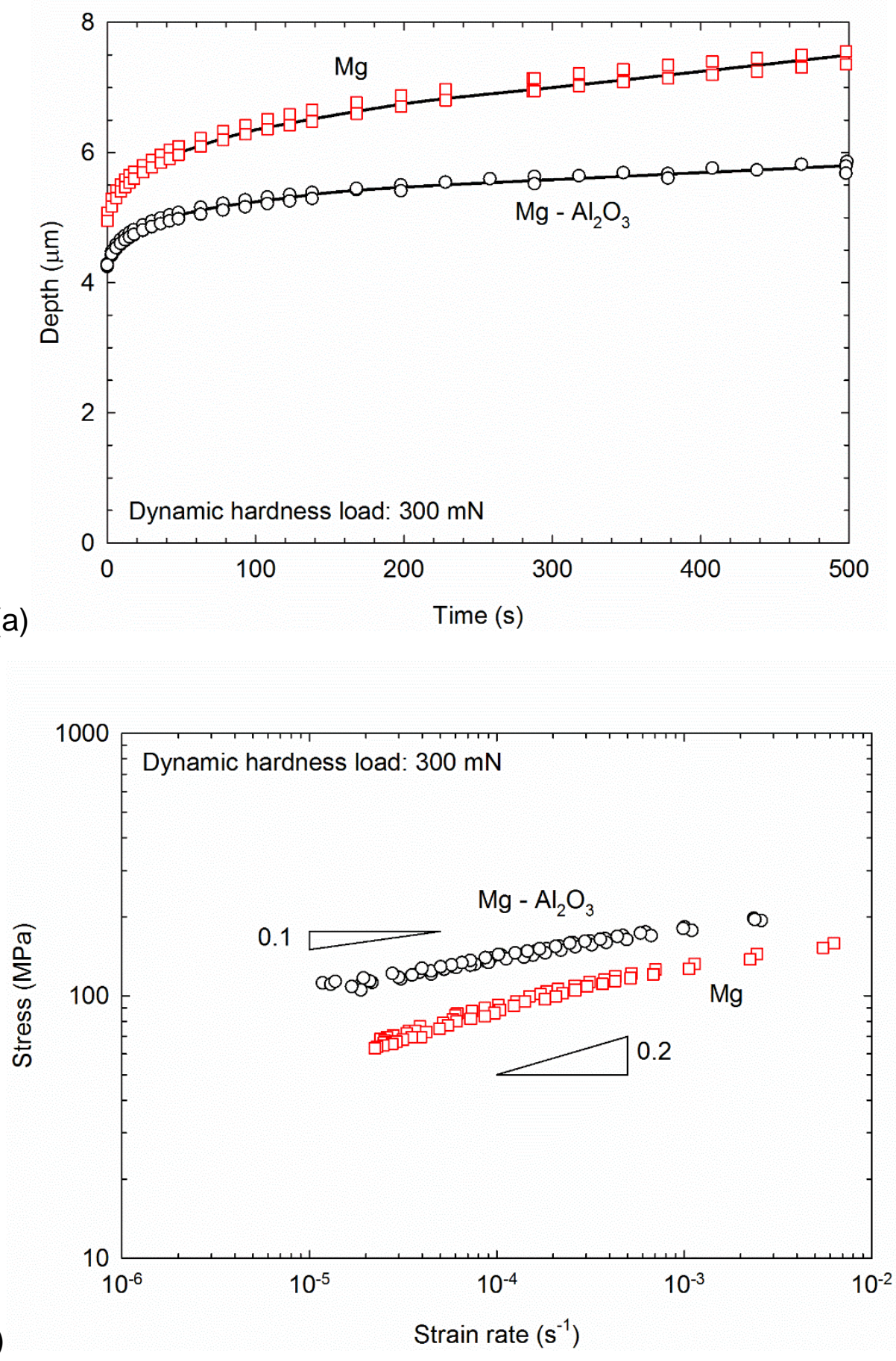

Figure 6 - (a) Depth vs time data and (b) room temperature stress vs strain rate curves determined by dynamic hardness testing; data for pure magnesium processed by HPT is also shown for comparison. 